\title{
Teaching Photography via Photography
}

\author{
Ben McDonnell
}

\section{Manchester Metropolitan University, United Kingdom}

\begin{abstract}
:
This reflective paper draws on an evaluation of current online pedagogy but also the authors practice as an artist that revolves around forming a relationship between image and sound. As such 'Listening' and 'Looking' are used as a broad structure for six short essays that draw on experiences of moving to online delivery to consider the virtual classroom as an amorphous, fluid space that can be both problematic but also present opportunities for innovative teaching and learning.

In addition to the six reflective essays; Latency, Volume, Spaces to Speak, Lebenswelt, Screenshare and The Thingness of Making, The Thingness of Teaching the article draws on an anonymous survey of second and third (final) year undergraduate students and an online conversation group initiated with colleagues that teach at undergraduate and post graduate level at both Manchester School of Art and the Royal College of Art. Rather than propose a definite set of conclusions the article suggests that the online platform is inherently a visual one, but using listening as a way of understanding it could open up the possibility of creating a teaching space that is concurrently difficult to grasp but potentially easily accessible and less hierarchical.
\end{abstract}

Keywords: Pedagogy; Online Pedagogy; Listening; Photography; Lebenswelt; Screen Share

Received: 20 July 2020

ISSN 2056-757X

Revised: 12 August 2020

Accepted: 1 September 2020

https://doi.org/10.18646/2056.73.20-019 


\section{Provocation: Online Tutorials}

Let's pretend the glass has got all soft like gauze, so that we can get through. Why, it's turning into a sort of mist now, I declare! It'll be easy enough to get through-' She was up on the chimney-piece while she said this, though she hardly knew how she had got there. And certainly the glass was beginning to melt away, just like a bright silvery mist (Carroll, 1871).

A large part of my teaching involves giving individual and small group tutorials for L5 and L6 students on the Photography BA course at Manchester School of Art. I try to engender a student focused conversational approach in both forms of tutorials, as such, this type of teaching seems easily suited to a direct transference to a digital platform. But does the glass of the screen 'melt away turning into a bright silvery mist' when giving tutorials online? I want to use this provocation to reflect on the tools that facilitate online dialogue, reflecting on how this influences teaching and learning. I shall focus on the shift to image based teaching, latency and listening and screen sharing.

Figure 1: 'I Want to Contribute to the Discussion', a hand signal used by Extinction Rebellion as a quick way of communicating on video conferencing.

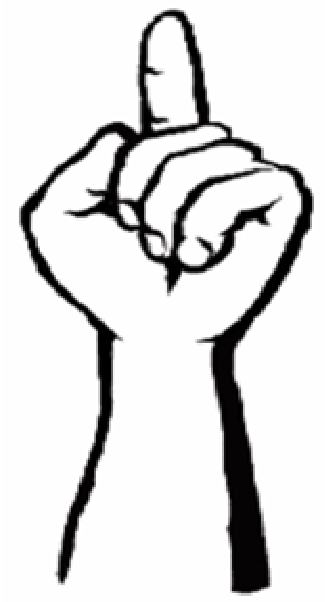

In order to prepare for online tutorials I attended a number of training events and seminars. Key to highlighting the differences between online and 'real world' group interaction was a training session I attended with Extinction Rebellion (XR) who have used Zoom as their primary online meeting tool for a long time. XR have developed hand signals to communicate as a way of getting around the audio visual latency that is inherently part of online communication. Microphones are muted (unless speaking) and a series of nine hand signals are used to show agreement, raise a point or object. The muting of microphones and use of hand signals highlighted to me that unlike a conversation in person or a phone call, when using an online platform the image is the primary form of communication. Due to the technical limitations of online communication platforms such as Zoom there is something unavoidably lost in communicating aurally, making it clear that there is a need to actively engage with the possibilities of the visual online medium in teaching, to both make up for what is lost in, and in some circumstances maybe even exceed, the rhythm of face to face communication.

International Journal of Management and Applied Research, 2020, Vol. 7, No. 3 


\section{Listening}

\subsection{Latency}

The delay inherent in digital communication, or latency, is long enough to experience when using Zoom. The 'temporal hiccups in information exchange that would never happen face to face' disrupt a natural flow in conversation. I found during tutorials I would accidentally speak over students and was apologising a lot for not letting them finish sentences. In a series of podcasts author and musician Dan Krukowski discusses the difference in experiencing analogue and digital time: "When we trade broadcast for podcast we give up the opportunity to experience time together in the same instant" (Krukowski, 2019:19).

Here Krukowski is discussing the difference between an analogue radio broadcast and digital podcasts. In face to face conversation we are physically and temporally sharing a space, we can interrupt one another, make agreement noises and fall silent without interrupting the discussion. But due to latency, during online tutorials each of us are in our own, incompatible, 'time spaces'. Silences, agreements and interruptions highlight the distance between us and make a flowing unstructured conversation very difficult.

This problem is amplified during group tutorials. With all 12 students experiencing time differently and each noise amplified by the groups open mics and we would interrupt each other regularly. I have instituted some of the good practice from XR, muting mics unless speaking and gesturing to agree work well, although initially this style of delivery seems more suited to top down delivery of information such as a lecture or presentation and is less successful at facilitating more responsive seminar style sessions.

\subsection{Volume}

"You are shouting! I'm trying to work!" is the daily rebuttal from my partner, as we deal with the challenge of sharing a working space in our small flat. Of course I deny this strenuously until she is on a call and I'm disturbed by her conversation and realise that a consequence of online platforms is a louder than usual delivery. I am shouting, and so is she, and possibly all my students as well.

We are separated in time by latency, inadvertently shouting at each other in order to be heard over the gap. The vision of my tutor group all wearing headphones and shouting into their computers put me in mind of early blustering telephone communication, comedic at first but on reflection made me reflect on equality of voice. Was the tutor group becoming a forum for those who can shout the loudest?

This is not a new problem of course, trying to give an equal platform to members of a group is often challenging. In some ways the digital platform offers an equality of space (visually we all occupy the same amount of space, priority isn't given to any one participant) but does it offer an equality of voice?

There is an increased level of intimacy that a screen based interactions hold. Some students requested not to have these interactions as they can be invasive of our private spaces (S.H. Appendix 1)

International Journal of Management and Applied Research, 2020, Vol. 7, No. 3 
From a student perspective having to project yourself into a space, and having your tutor invading your space (students are often working from bedrooms in the family home for example) can seem overwhelming. As a result, a number of students prefer to communicate without the camera, while others have better or worse internet connections, quality of microphone and so on.

'I find it hard as my laptop microphone isn't clear and therefore my ideas aren't projected clearly.' - (L5 Student Appendix 2)

As a lecturer I am confronted with a number of boxes, some blank, some containing fuzzier images and quieter audio. In this scenario I think it could be easier for students that are less inclined to forcefully communicate in a group to 'slip through the net' and remain unheard.

It could be that recognition of our shared situation, acknowledgement that we are all trying to come to terms with online teaching together offers a form of solidarity that in turn enables students to 'raise their voice'.

When professors bring narratives of their experiences into classroom discussions it eliminates the possibility that we can function as allknowing, silent interrogators. It is often productive if professors take the first risk, linking confessional narratives to academic discussions so as to show how experience can illuminate and enhance our understanding of academic material. But most professors must practice being vulnerable in the classroom, being wholly present in mind, body, and spirit (Hooks 1994:21).

In the case of online group discussion 'taking the risk' of lowering barriers is almost inherent when working from home. Students get a glimpse of your home life as partners, children and pets make unexpected appearances in the classroom. Acknowledgment of this situation rather than trying to hide or over professionalise one's teaching context, in my case disclosing that 'my partner tells me I'm shouting', does seem to engender a less hierarchical environment, making me appear less like a 'silent interrogator'. This acknowledgement of vulnerability can contribute to an environment in which every participant feels more able to express themselves. The simple observation that everybody does not have an equal voice in this (or any) community and a discussion around how to circumnavigate these problems might help promote a more equal conversation. It could be that unlike the traditional classroom, tools afforded to us by video (Zoom, Teams) and other asynchronous communication platforms (Padlet, Socrative) might be able to help re-address the imbalance and provide alternative forms of allowing for a more equal voice in our teaching and learning.

\subsection{Spaces to Speak}

I have tried structuring sessions to give students time to introduce ideas without interruption. Each learner was given a set time to explore an idea, they were asked to prepare in advance so they had material to discuss and we could still institute the XR techniques while watching/listening to the presentations. This format started to circumnavigate some of the issues with latency.

International Journal of Management and Applied Research, 2020, Vol. 7, No. 3 
Figure 2: Spaces to Speak Revision Part II, 2010 Céline Condorelli Courtesy Cell Project Space, London. The artist has made movable seating to facilitate a flexible public forum

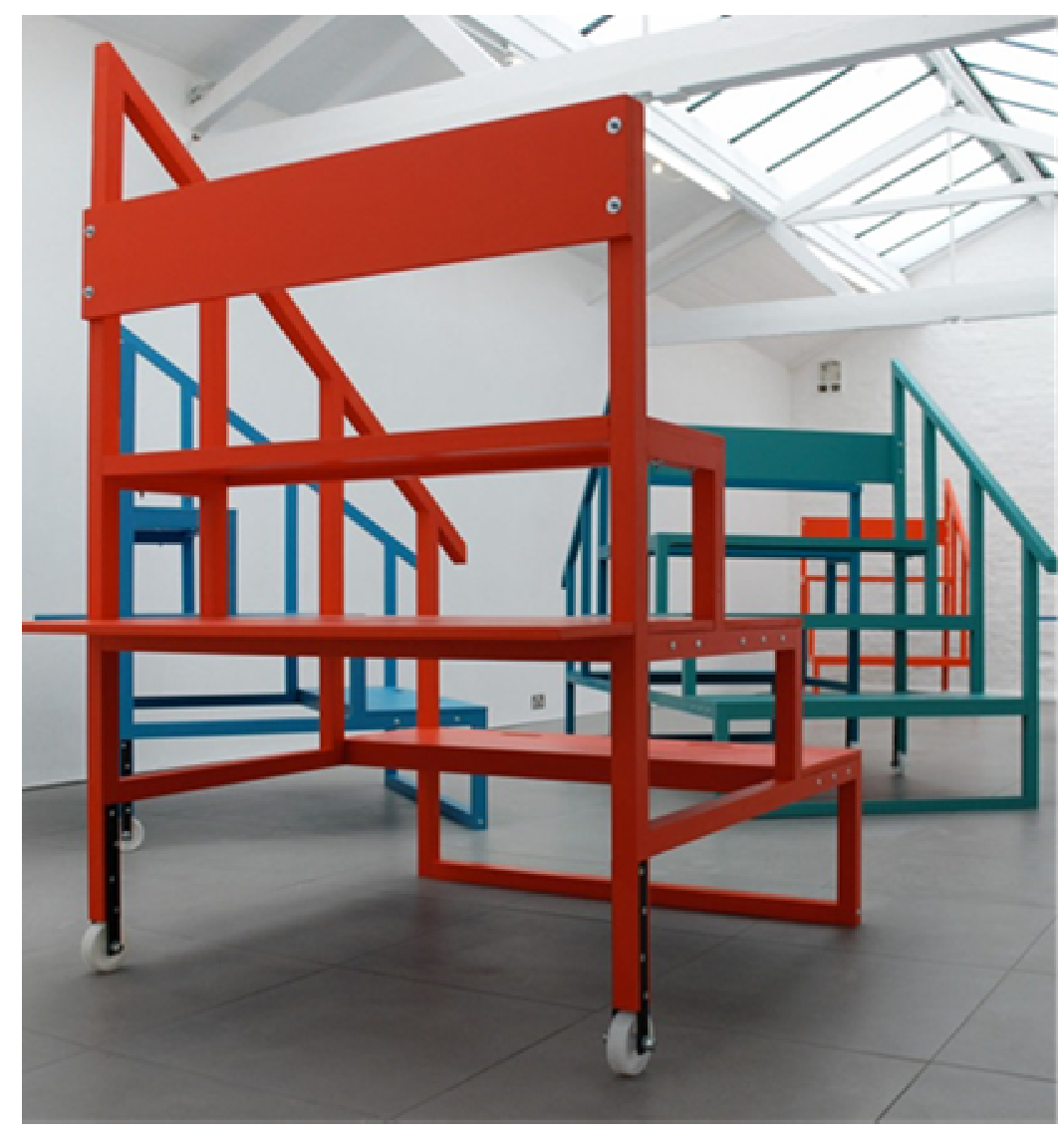

Stephen Brookfield describes discussion as a 'disciplined and focused exploration of mutual concerns' (Brookfield, 1999) and the structured methodologies he suggests in Discussion as a Way of Teaching could be adapted well to online teaching and could allow for a more productive session. Brookfield suggests a system of ground rules, and I could see how a list of 'rules for Zoom' adapted from XR and my own experience and the experiences of colleagues and learners would be a useful resource. The Circle of Voices, one of Brookfield's techniques for encouraging discussion, could offer a way of allowing each of the students a voice, and despite occupying different 'time spaces' would allow for a reflective period of listening.

After this silent period the discussion opens with each person having a period of uninterrupted air time. During the time each person is speaking no one else is allowed to interrupt (Brookfield, 1999:11).

This technique, similar to the micro presentations I experimented with, makes use of silence and sequential delivery to circumnavigate the issue of latency. I am keen to keep experimenting with this and other structures Brookfield suggests for discursive teaching during my upcoming group tutorials. 


\section{Looking}

Figure 3: courtesy of the author, taken at 'Casting Out the Self' exhibition by Dominic Hawgood, 2020. The artist has created a work that induces mild visual hallucinations when the flickering screens are stared at.

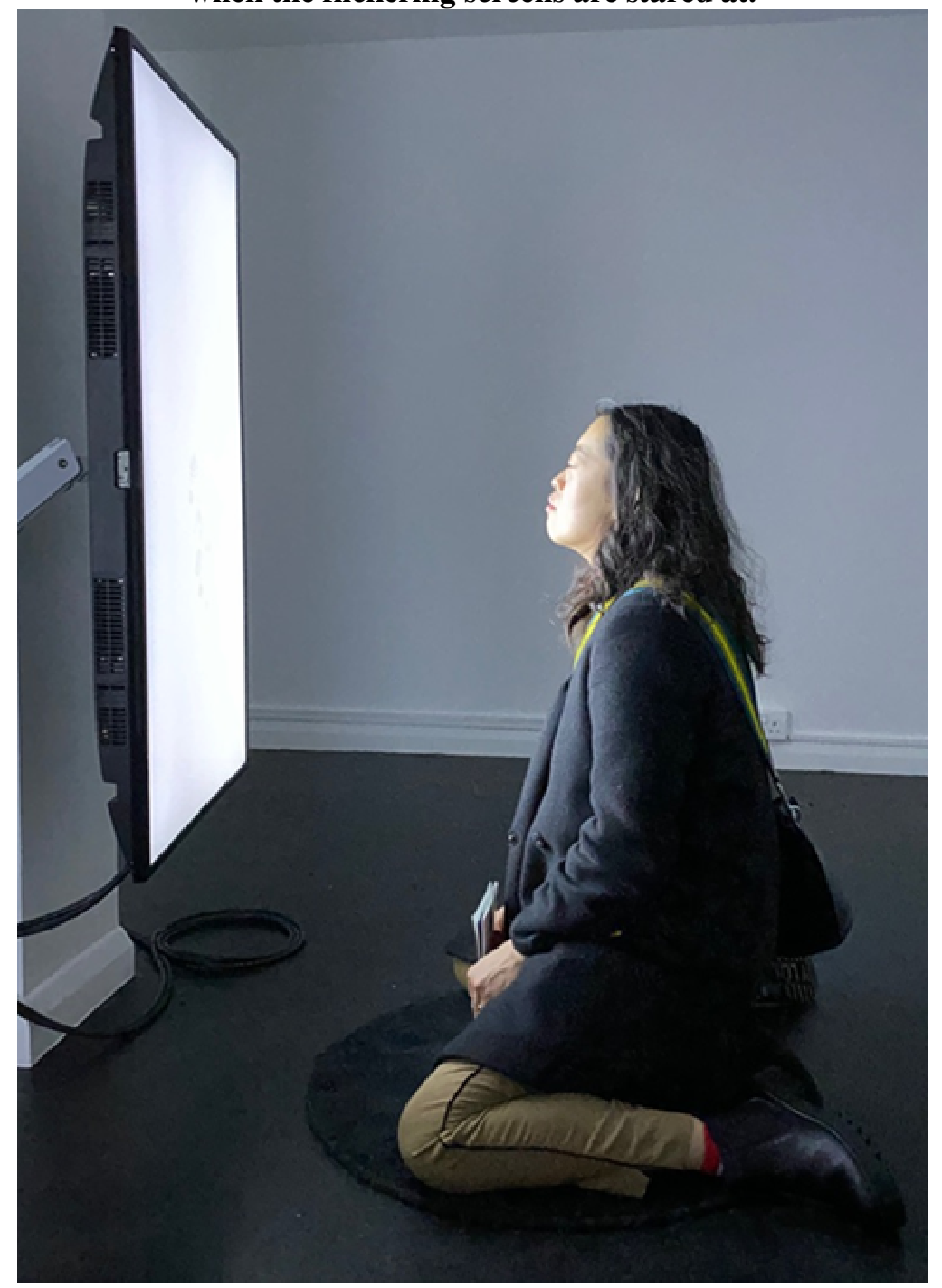

\subsection{Lebenswelt}

Even if Brookfield's techniques were implemented successfully, we would all still be in our own 'time spaces', delineated by rectangles each of us is unable to communicate in a shared space or a shared time.

The Lebenswelt, literally "life-world," or "world in common" as Arendt defines it, is the framework from which both understanding and political judgment (from the point of view of the political actor and/or spectator) can arise. The world in common is where speech, thought, and action take place, thus possessing unquestionable meaningfulness, and enabling common existence (Emmelhainz, 2020). 
Here Irmgard Emmelhainz asks if we can share a world beyond representation, using Hannah Arendt's lebenswelt as an example of a space in which draws together a community, in which opinions can be incommensurable but still discussed and shared. Brookfield defines discussion as 'disciplined and focused exploration of mutual concerns but with no end point predetermined in advance' Both examples establish a shared space, in which views are exchanged with a dialogic process, with no fixed outcome.

In regard to online teaching the importance of trying to create a shared space that we can simultaneously occupy, a lebenswelt, could offer a way of trying to overcome the separation caused by latency.

I have found screen share and whiteboard to be invaluable tools in helping to create a participatory, shared space. Screen share allows us to see each other's viewpoint, virtually using the same pair of eyes and whiteboard offers a physical space in which we can all participate concurrently.

\subsection{Screen Share}

As teachers and learners of photography we are seemingly ideally suited to sharing work through the screen. We are well positioned to contextualize images having developed a fluency in the language of images. The screen share tool feels like an extension of the tutorial process. To help students situate their work among the discourse around contemporary art, we often look at other artists' work, articles and videos on my laptop and this has continued through online teaching. It is really useful to be able to copy links and make notes using the 'chat' that students can download and keep at the end of the tutorial.

I have used the whiteboard tool as another way of collective note-talking. In this instance it is a simulation of the very basic collective note taking I do in group tutorials. During these face to face tutorials I cover the table with a large sheet of paper, we all have coloured pens and as the discussion flows we write notes that seem pertinent. At the end of the session a member of the group will take a picture of the 'tablecloth' and share it with the group. Just as this shared experience of research opens individual students to a collective form of knowledge gathering/information processing the virtual whiteboard can do the same. As the marks are left instantaneously this can provide a visual collective experience that talking can't, and the anonymity of the comments seems to lead to very honest feedback that a student would maybe feel less comfortable sharing in a classroom.

[When asked if they thought screen share was a useful tool] 'Yes! Very helpful as it helps see other people's ideas clearly' (L5 Student Appendix 2)

The ability for both me and the students to share their screen with the group offers a shared way of seeing, much in the same way as seeing a film with a group offers a shared experience using tools that allow us to see simultaneously. The whiteboard allows a visual form of research and note-taking to unfold in a shared timeframe. Both can help contribute to a sense of shared experience, our 'lebenswelt'.

International Journal of Management and Applied Research, 2020, Vol. 7, No. 3 
Figure 4: courtesy of the author, L5 tutor group, 2020.

Students document the 'tablecloth' at the end of a tutorial

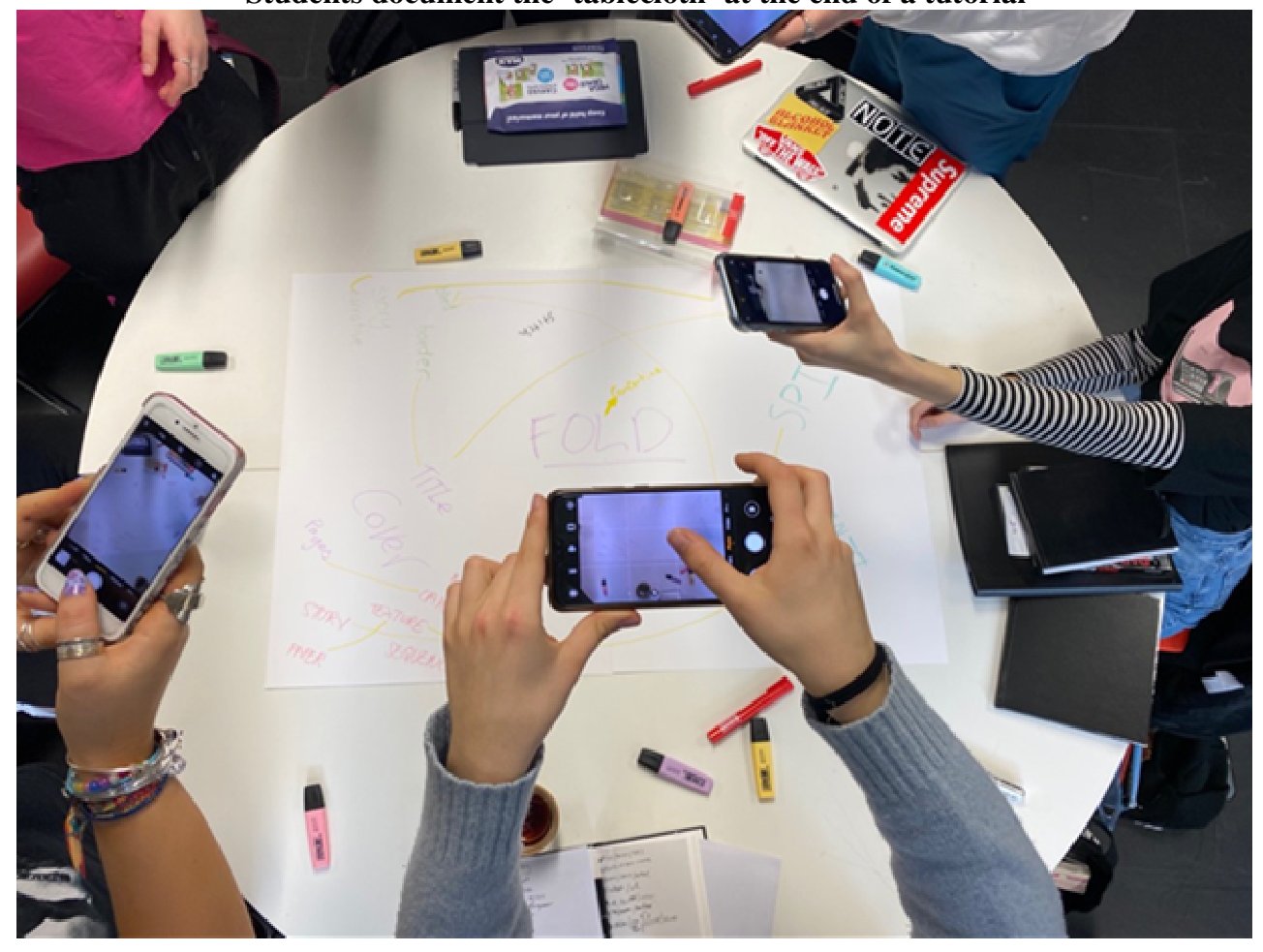

\subsection{The thingness of making, the thingness of teaching}

Figure 5: courtesy of the author, Teaching Sketches, 2019. Scans from my notebook documenting sketches made during tutorials in which I help map out the ideas in a student's essay.

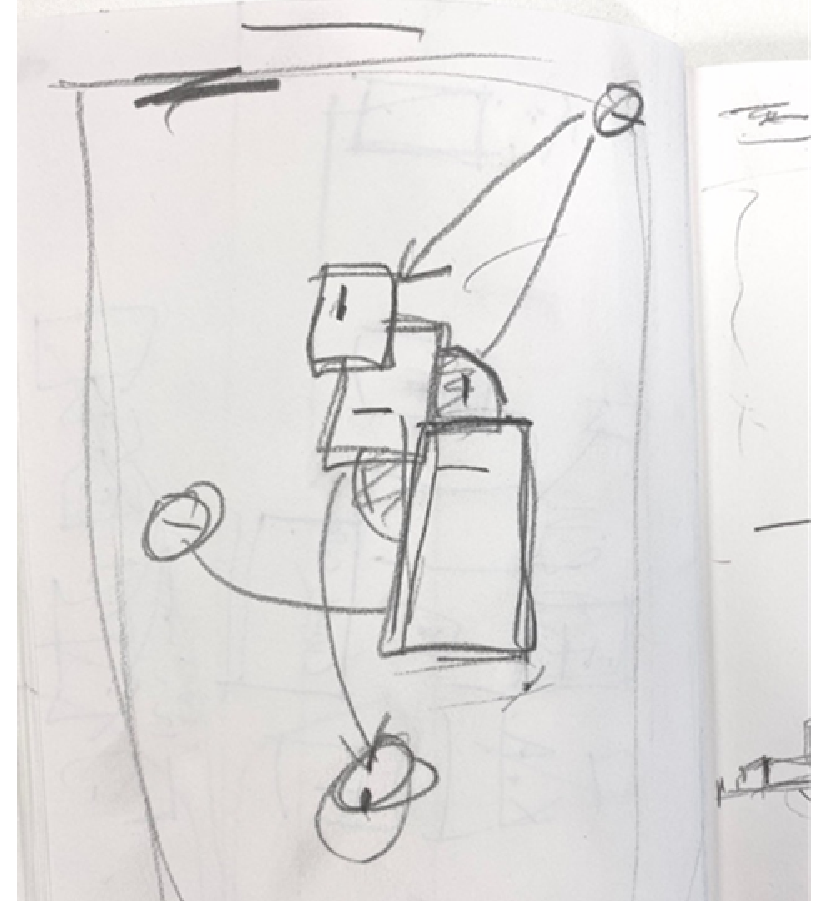

International Journal of Management and Applied Research, 2020, Vol. 7, No. 3 
'Looking at an image on a screen can't compare to holding a print. I wonder if tutors will see the work differently on a screen to having prints in a portfolio box too.' (L6 Student Appendix 2)

'Many of the activities we have completed over the past two terms that have been particularly useful (the guerrilla exhibitions and gallery visits) this was based on working with a space and being able to navigate around it and use it to address issues we may have come across within the practice, online this cannot be done and there for it seems that we could lose an essential part of the teaching method that I have found particularly useful' (L6 Student Appendix 2)

Two comments from a Padlet I set up final year undergraduate students highlight particular worries about the making and presentation of work for final assessment and wider issues around the study and presentation of objects via online teaching. I think they highlight materiality in two distinct ways, how are things seen online? and in what context do they exist?

There is an obvious challenge in assessing physical work, 'things', without having seen them. When every aspect of the work, the weight, the texture, the scale, has been reduced to an image assessing can be challenging. The art school practice of discursive assessment doesn't entirely mitigate these problems but certainly gives assessors greater support when marking. Having two or three opinions in a conversation around the work helped by giving academic staff more points of reference allowing them to 'triangulate' their opinions.

It is my view that in text-based subjects double-marking and moderation are viewed as serving primarily quality assurance and regulatory purposes rather than being an approach that, in part, defines pedagogy. In contrast, for art and design lecturers, moderation conversations are a key site for judgement making. In the words of one lecturer I interviewed 'assessment happens in that dialogue' (Orr 2010:10).

The guidelines for assessment at the university I work for definitely support Orr's that moderation is a regulatory system rather than an integrated part of the process. As a course we often have a more discursive approach to assessment and a lot of the work is if not moderated then discussed with other members of staff. I believe this approach is, as well as being useful for us encouraging peer learning, is also beneficial for students. When 'assessment happens in that dialogue' it could be reassuring for students that while their work will undoubtedly be seen differently through the screen, it will be seen fairly. As work is made as part of a discursive process, it should be assessed as such, and even more so at a time when we are physically distanced from each other.

As the second student pointed out, a lot of our teaching considers not only the 'thing' itself, but the context it is made and shown in. This in turn prompts questions around who is seeing it and what relationship they will develop between themselves, the 'thing' and it's context. The student's comment raises a lot of questions about the

International Journal of Management and Applied Research, 2020, Vol. 7, No. 3 
materiality of the virtual space in which we work together and present work to each other.

During the first week of my MA at the Royal College of Art I was told NOT to bring images on a screen to tutorials, but to 'show the work'. This didn't mean we couldn't make screen-based work of course but it was meant to stop conversations about 'potential' work. Images on the screen could be printed at any size, on any material or edited in any number of ways. This material slipperiness makes it very hard to discuss the work, even in person. Online, students work ceases to have a material presence and remains in flux. When viewed it has to contend with my cluttered desktop MacBook desktop, which in turn sits next to my half finished coffee and my partner working opposite me. In this way students work is decontextualized, looses itself, perhaps functioning as one of Hito Steyerl's 'poor images':

The poor image has been uploaded, downloaded, shared, reformatted, and reedited. It transforms quality into accessibility, exhibition value into cult value, films into clips, contemplation into distraction. The image is liberated from the vaults of cinemas and archives and thrust into digital uncertainty, at the expense of its own substance. The poor image tends towards abstraction: it is a visual idea in its very becoming (Steyerl, 2009).

Students' work which is carefully edited for publication or intended for a gallery space becomes 'thrust into digital uncertainty'. The image is separated from its materiality and the student looses control over its context. Work that was intended to be printed $2 \mathrm{~m}$ tall or viewed in a particular sequence and place on a page is now viewed in a window on my 15" laptop screen. In one way this is a liberation, there are certainly advantages from being separated from substance, but in another of course this is also a reduction, something is lost.

I see language and conversation more and more as a material. Even I do not always see what they are working on I can imagine (R. G. Appendix 1).

I agree I think the conversations are just as important as any other material - having the time and space get more confident using the material of language must be a positive thing (S.H. Appendix 1).

I am drawn to this excerpt of a conversation between two colleagues as it highlights the shift in materiality when teaching online. Moving away from the artwork and away from the physicality of the classroom allows us as teachers to concentrate on the material of our practice. As S.H. mentions having some time to consider the material of our language decontextualized from the institution and our studios must be a useful exercise.

I am starting to question my teaching in the same way, has it become a 'poor image' or differently material? Released from the architecture of the institution the students engage differently through the screen. The material context of our shared learning has changed and we are still trying to understand the consequences of this. There are positives, as conversations with my colleagues point out. Online teaching, like the poor

International Journal of Management and Applied Research, 2020, Vol. 7, No. 3 
image can be more fluid, easy to access, more integrated with multimedia content and often less demanding on students' time. But of course as in any translation or exchange something is lost, the instantaneous communication and shared learning experience that face to face teaching offers.

\section{Conclusion}

Through the six short reflections on listening and looking in relation to online pedagogic practice I hope to have highlighted the problematic relationship between listening and time that is inherent in digital communication and the separation this can cause. As well as this, the dematerialisation of both my students work and my own practice as a result of our exchange being conveyed online and predominantly through images, presents a practice that is both in-flux and decontextualized. Conversely at a point of change there is always a chance to rethink and readdress. For example, can a shift toward the predominantly visual medium of online teaching and thinking about this in relation to listening allow opportunities for a more equal student voice and a less hierarchical learning environment?

The same fluidity of the digital image space that threatens to decontextualize students work could conversely offer us, as pedagogues, an opportunity to reinvent the classroom every time we teach. The architecture of a university can be overwhelming and intimidating and it is very hard to accommodate a wide range of learners needs in a fixed architectural space. In an online environment these issues can be addressed relatively easily, the virtual learning environment can shrink and expand as needed, videos can be subtitled and text, images and other material can be enlarged, read, saved and shared. Perhaps more importantly it gives as an opportunity to create a more equal platform, just as our video windows can be made all the same size in the digital classroom, the opportunity to 'speak' can also be normalised. Use of chat functions, recorded messages, anonymous messaging, if used with care, can help readdress inequalities that are harder to manage in a seminar or lecture theatre.

The structure of the institution provides a framework in which communities can be formed, and this happens often without direct intervention. Discussions in an open working space, while leaving a lecture theatre or waiting in a cue for coffee are a valuable part of the learning experience and help give a group of students a collegiate sense of identity. In order to foster this shared experience, or 'lebenswelt', online we would do well to return to listening. Structured listening in the form that Brookfield suggests could help form a shared sense of space but in addition reimagining the image-based world of the online classroom as an auditory experience be helpful to unravelling both the challenges and advantages of the virtual classroom. Understanding the lebenswelt of the online learning space as one that is noisy, amorphous, polyphonous and leaky could help us facilitate structures that allow us to congregate and listen together, seeing and hearing across the gap that separates us.

International Journal of Management and Applied Research, 2020, Vol. 7, No. 3 


\section{Appendix 1: Colleague Online Discussion Group (as of 17/4/20)}

An ongoing resource for colleagues across various levels (Teaching assistant, visiting lecturers, technical teachers, senior Lecturers) from a range of universities including (so far) Manchester Metropolitan University, the Royal College of Art, University of the Arts London.

Hi everyone,

As part of my PGCE we have been asked to critically reflect on our practice using a reflective model (I've chosen Brookfield's Four Lenses as it seems like a suitably photographic metaphor!).

Overview: https://bit.ly/3jq7ERc

In Depth: https://bit.ly/3lsYDsw

One of the 'lenses' is reflecting on colleague experience, I thought this could be a useful provocation to start a discussion around teaching (specifically art/photography) as an online practice.

Thinking about the lens and the idea of perspective. If we take any lense think about its lines going through. With lines I mean the angle the light falls and reflects at the end of the camera. So those lines are not just effected by other people but also the surrounding and the environment, lighting or even temperature. (all is more seen a metaphor but works really well for photography) (RG)

Love the idea of this. Lines is a nice way of thinking about the interaction of things people and place. (BM)

We are all probably working harder than ever at the moment and have a lot of screen time as well as other work/life issues to deal with so I understand completely if you feel unable to contribute substantially. If you would find it useful I'm sure we would all be interested in your contributions, if you don't have time lets meet up in the flesh when we are all able to!

Provocations, please add thoughts reflections and links below each title:

Teaching photography via photography

What it means to be teaching photography through the screen, specifically thinking about individual tutorials using platforms such as zoom. (BM)

Having had some zoom calls with students I think a lot about how we have time. I teach but also my role is mainly technical (and do not have much 1:1 time and explore individual projects), at least in the job description (I dont see it only that way) but I was thinking how the lines blur. We are having a tutorial more about reference and ideas rather than technical support. We are talking about alternative ways to the darkroom or the studio. But that cannot be replaced. I think its more about find a process or something creative. Most student also travelled back home and do not have the facilities that the college has. It is about finding things together with the students they always wanted to explore or haven't had time. Research, reading or writing. (RG)

I have had quite a few different experiences whilst teaching online that have stood out. But perhaps my main observation (that may not be the case for everyone) but is a sort of heightened intimacy - or perhaps false intimacy ... and awareness of both yourself and the other person within the conversation. Unlike when there is a piece of work physically in front of us we are shifting from either no work and just a conversation or images of the work and then back to ourselves confronting each other simultaneously. This switch can be distracting but it can also lead to a more open conversation in some cases. Tutorials have been expanded in some cases with students sending work intermittently and I think I am more inclined to send a reference to someone who I have had a digital conversation with throughout the week as this digital trail is already in place. I suppose trying to recapture the immediacy of conversation and bumping into someone in passing. (SH)

The thingness of pictures, the thingness of teaching.

I'm sure we all discuss the materiality of images (digital or analogue) a lot with students, does teaching remotely change these discussions? What is the materiality of teaching? (BM)

I think through this whole process of teaching online makes us all more realise how physical photography is. It is about finding a substitute. And we do not need a replacement of the screen, as in editing images for example. We need to consider the material around us.

See what transparent material we have around us instead of our film negatives? How can we scan without having a scanner? Often we need light for any of the photographic process. It becomes about observing what we have given. Or a light sensitive material. What about transparent paper? Or using words to describe a process that's not possible. I think limitations are a good thing. It slows things down and while slowing down there is more time to reflect. It gives us time to reflect about our teaching. What is it we are doing while the whole life is now online? Exhibitions, talks, podcast and free art movies. At the moment I think teaching is about sharing and talking, nothing more. It is about questioning but also reassuring.

Very much this. It feels somehow dishonest to be toeing the party line and saying 'artists are creative, be creative and find a solution' some things take time, discussion and reassurance. Coming back to the idea of materiality. I see

International Journal of Management and Applied Research, 2020, Vol. 7, No. 3 
language and conversation more and more as a material. Even I do not always see what they are working on I can imagine. (BM)

I agree I think the conversations are just as important as any other material - having the time and space get more confident using the material of language must be a positive thing $(\mathrm{SH})$.

Its maybe also not thinking about quality more about the process. It's not about what equipment you are using, it is about the idea, the thinking process. And that is something I always believed in and I think especially for photographer photographers, always talking about the best technology and the better the picture will realise it is not true (RG).

Latency

The delay inherent in digital communication, or latency, is long enough to experience when using Zoom. The 'temporal hiccups in information exchange that would never happen face to face' disrupt a natural flow in conversation. I found during tutorials I would accidently speak over students and was apologising a lot for not letting them finish sentences. In a series of podcasts author and musician Dan Krukowski discusses the difference in experiencing analogue and digital time;

'When we trade broadcast for podcast we give up the opportunity to experience time together in the same instant.

Here Krukowski is discussing analogue radio broadcast and digital podcasts. In face to face conversation we are physically and temporally sharing a space, we can interrupt one another, make agreement noises and fall silent without interrupting the discussion. But due to latency, during online tutorials each of us are in our own, incompatible, 'time spaces'. Silences, agreements and interruptions highlight the distance between us and make a flowing unstructured conversation very difficult. (BM)

I suppose this is interesting in what I said about the increased level of intimacy that a screen based interactions hold. Some students requested not to have these interactions as they can be invasive of our private spaces. But the fact they are "incompatible, time spaces" also adds a cumbersome layer to these interactions that might also be a cause of anxiety and frustration. (SH)

Teaching spatially

Putting images in a spatial context and working through issues such as scale, material, positioning etc is a process I find particularly rewarding. As with my art practice I consider teaching a spatial activity, how does this translate online? What is the online space we teach in? (BM)

I feel similar about it. But it's also comparing it to the idea of the white wall. That is limiting. What about the space in front of your door? Or what if you used your living room. How would you install your work there? What about walking around the street. Posters glued and pasted to the wall even though its material became the space. (RG)

Yeah absolutely, I think as well as artists/teachers thining critically about the virtual space and the space in which we view students work. I am very aware that what would have been viewed as a $2 \mathrm{~m}$ print is now reduced to a small window on my 15 " laptop next to a picture of me and my student! I am always sitting when I encounter this work also, which I don't like - the physicality of teaching and being with art seems to be lost very quickly. It would be good to get some of this back somehow. (BM)

What if all around you becomes part of it? I know it is all very fictional but thats what art often is. It's not that we always have a space or even a big enough studio to play. I always like to think of Heidi Bucher how he traces her surroundings by making imprints in empty houses. Or what about Monster Chetwynd. Her materials are every day. To my shame I didn't know Heidi Bucher, im so into her work - amazing! (BM)

But translating it online. Its is very challenging. Thinking about virtual shows. I like when you see guided tours, as in an existing exhibition being documented. I struggle to imagine it as VR or just a duplicate online. I prefer thinking a blog could be interesting because people take time and also see the process. But there is nothing comparable online to a space and environment to respond with art work with. (RG)

The idea of a virtual show as a simulacrum of a 'real' show is dishonest and very much a rip-off for students. However I think an online presentation of something (I like the idea of an online studio visit, where a working process is discussed. Images could be presented with texts, videos probably work much better than in person at a degree show, links to research etc etc) could be valuable. I think that the degree show is a problematic area anyway. The positive outcome of this could be the rethinking/prioritising of what/why/how we show work. (BM)

Zoom I see as a platform for conversation and share a screen. It allows you to see each other's space but that makes it feel even more distant. Gestures are missed. You see your favourite background. (RG)

I'm really into this: https://bit.ly/3jo5Ubj At the moment. Love the idea of a Lebenwelt, and wondered if it was possible to create this online in a shared teaching space. "The Lebenswelt, literally "life-world," or "world in common" as Arendt defines it, is the framework from which both understanding and political judgment (from the point of view of the political actor and/or spectator) can arise. 1 The world in common is where speech, thought, and action take place, thus possessing unquestionable meaningfulness, and enabling common existence." Also really into bell hooks for general inclusive pedagogy stuff: https://bit.ly/31CPd5X (BM)

International Journal of Management and Applied Research, 2020, Vol. 7, No. 3 


\section{Appendix 2: Level 6 Student Feedback (as of 17/4/20)}

Figure 7: Screenshot from Padlet discussion with final year BA students, 2020.

padlet

padlet.com/bmedonnell1/mmz19pg3spr

\section{Teaching and Learning online}

As part of my PGCE we have been asked to critically reflect on our practice using a reflective model (I've chosen Brookfields Four Lenses as it seems like a suitably photographic metaphor!). One of the 'lenses' is reflecting on student experience, I thought this could be a useful provocation to start a discussion around teaching and learning (specifically art/photography) as an online practice.

BEN MCDONNELL APR 08, 2020 05:49PM

\section{Learning Spatially}

Putting images in a spatial context and working through issues such as scale, material, positioning etc is a process I find particularly rewarding. As with my art practice I consider teaching and learning an activity that happens in relationship to the space we work in. How does this translate online? What is the online space in which we learn?

I am really interested in curation, so for me having a physical space to exhibit work is much more exciting than curating in a digital space. My practice has always been quite physical, even when engaging in a 3D Design project, so I do normally find working digitally to be rather challenging and being in quarantine has helped me with this. Most recently I have begun to create video work, which
being is just as easliy observed within a digital space as it is in a physical space. However I still think this is largely dependent on an artists vision for the display of their work. If an artist had considered personal blog may not express the original intentions of the artist, and may also change the way the work is read. The way we display our work can have a huge impact on the way it is interpreted, and for many it can become $a$ key part of the work. Being able to see my work in a physical space helps

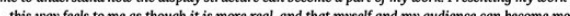
this way feels to me as though it is more real, and that myself and my audience can become more
engaged and build a connection with it Having said this I think it is important to be able to ada and change our way of working, to allow us to work through situations, such as the one we currenti find ourselves in. We are still in control of the work we can make, and we might discover new things about our practice when we are forced to work in a more digital way. - - ANowrmous

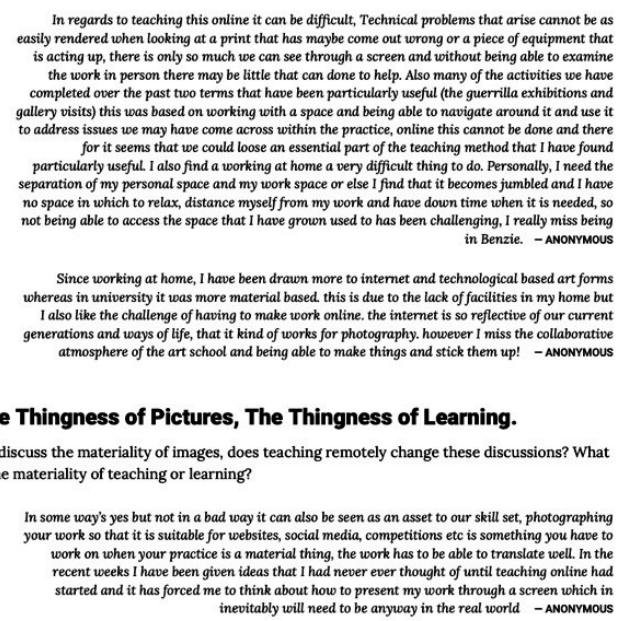

inevitably will noed to be anyway in the real world

\section{Appendix 3: Level 5 Student Feedback (as of 17/4/20)}

Figure 8: Screenshot from Padlet discussion with second year BA students, 2020.

padlet

padlet.com/bmedonnell1/958/4c11cptoe8er

\section{L5 Teaching and Learning Online}

As part of my PGCE we have been asked to critically reflect on our practice using a reflective model (I've chosen Brookfields Four Lenses as it seems like a suitably photographic metaphor!). One of the 'lenses' is reflecting on student experience, I thought this could be a useful provocation to start a discussion around teaching and learning (specifically art/photography) as an online practice.

BEN MCDONNELL APR 15, 2020 01:57PM

\section{Spaces to Speak}

Does the shared experience of Zoom make us all more 'equal'? Do you feel comfortable joinin in a discussion? Does seeing each others private spaces (bedrooms, my cat wondering past etc!) make you feel more connected, or the opposite?

\section{Volume}

Do you find yourself speaking in a raised voice when using zoom (I do!) is this a problem, $\mathrm{d}$ you find it hard to be heard? Do you feel comfortable expressing yourself in this format?
I find it hard as my laptop microphone isn't clear and therefore my ideas aren't projected clearly. I'd

\section{A Shared World}

Using screen share, whiteboard etc to create more of a shared space online. Are these useful tools? Do they help us work as a 'team'?

International Journal of Management and Applied Research, 2020, Vol. 7, No. 3 


\section{References}

1. Brookfield, S. (2006), Discussion as a Way of Teaching, Available from: https://static1.squarespace.com/static/5738a0ccd51cd47f81977fe8/t/5750ef4862cd 947608165d85/1464921939855/Discussion as a Way of Teaching Packet.pdf [accessed 17/4/20]

2. Carroll, L. (1991, orig published 1871), Through the Looking-Glass [online ebook] Gutenburg. Available from: https://www.gutenberg.org/files/12/12-h/12h.htm [accessed 17/4/20]

3. Emmelhainz, I. (2020), "Can We Share A World Beyond Representation", E-Flux Journal \#106 [online] Available from: https://www.eflux.com/journal/106/314167/can-we-share-a-world-beyond-representation/ [accessed 17/4/20]

4. Hooks, B. (1994), Teaching to Transgress, Education as the Practice of Freedom, New York: Routledge.

5. Krukowski, D. (2019), Ways of Hearing, Massachusetts: MIT Press

6. Orr, S. (2010), 'Making Marks: Assessment in Art and Design' Networks Magazine, No. 10, pp. 10-14. [online] Available from: http://arts.brighton.ac.uk/_data/assets/pdf_file/0004/65308/Susan-Orr-articleIssue-10-pp-9-13.pdf[accessed 17/4/20]

7. Steyerl, H. (2009), "In Defense of the Poor Image", E-Flux Journal \#10 [online] Available from: https://www.e-flux.com/journal/10/61362/in-defense-of-the-poorimage/ [accessed 17/4/20]

\section{Images}

Figure 1: Unattributed artist, Hand Signal for 'I Want to Contribute to the Discussion' [accessed 17/4/20] https://www.seedsforchange.org.uk/handsig.pdf All Seeds for Change guides are anti-copyright. Feel free to copy, adapt, use and distribute them, as long as the final work remains anti-copyright.

Figure 2: Condorelli, C.Revision Part II, 2010 Céline Condorelli Courtesy Cell Project Space, London[accessed 17/7/20] https://www.cellprojects.org/artists/celinecondorelli Image copyright Cell Project Space 2009.

Figure 3: McDonnell, B. Casting Out the Self by Dominic Hawgood at TJ Baulting Gallery 2020. Image copyright B. McDonnell 2020.

Figure 4: McDonnell, B. Level 5 Tutor Group 2020. Image copyright B. McDonnell 2020.

International Journal of Management and Applied Research, 2020, Vol. 7, No. 3 
Figure 5: McDonnell, B. Teaching Sketches, from ongoing series of sketches made during tutorials 2019. Image copyright B. McDonnell 2020.

Figure 6: Screenshot from Padlet discussion with final year BA students, 2020. Image copyright B. McDonnell 2020.

Figure 7: Screenshot from Padlet discussion with second year BA students, 2020. Image copyright B. McDonnell 2020.

Figures 2-7 cannot be reproduced without permission of the copyright holder. 